\title{
Influence of Nitrous Oxide Anesthesia, B-Vitamins, and MTHFR gene polymorphisms on Perioperative Cardiac Events: The Vitamins in Nitrous Oxide (VINO) Randomized Trial
}

\author{
Peter Nagele, M.D., M.Sc. ${ }^{*}$ [Assistant Professor], Frank Brown, B.Sc. ${ }^{\dagger}$ [Research \\ Coordinator], Amber Francis, B.S.N, R.N. ${ }^{\dagger}$ [Research Coordinator], Mitchell G. Scott, \\ Ph.D. $\ddagger$ [Professor], Brian F. Gage, M.D., M.Sc. ${ }^{\square}$ [Professor], J. Philip Miller, A.B. $\S$ \\ [Professor], and for the VINO study team ${ }^{\#}$ \\ "Division of Clinical and Translational Research, Department of Anesthesiology, Washington \\ University in St. Louis \\ †Division of Clinical and Translational Research, Department of Anesthesiology, Washington \\ University in St. Louis \\ FDepartment of Pathology \& Immunology, Washington University in St. Louis \\ $\square$ Division of General Medical Sciences, Department of Internal Medicine, Washington University \\ in St. Louis \\ §Division of Biostatistics, Washington University in St. Louis
}

\begin{abstract}
Background-Nitrous oxide causes an acute increase in plasma homocysteine that is more pronounced in patients with the MTHFR C677T or A1298C gene variant. In this randomized controlled trial we sought to determine if patients carrying the MTHFR C677T or A1298C variant had a higher risk for perioperative cardiac events after nitrous oxide anesthesia and if this risk could be mitigated by B-vitamins.
\end{abstract}

Methods-We randomized adult patients with cardiac risk factors undergoing noncardiac surgery to receive nitrous oxide plus intravenous B-vitamins before and after surgery or to nitrous oxide and placebo. Serial cardiac biomarkers and 12-lead electrocardiograms were obtained. The primary study endpoint was the incidence of myocardial injury, as defined by cardiac troponin I elevation within the first 72 hours after surgery.

Results-A total of 500 patients completed the trial. Patients who were homozygous for either MTHFR C677T or A1298C gene variant $(\mathrm{n}=98 ; 19.6 \%)$ had no increased rate of postoperative cardiac troponin I elevation compared to wild-type and heterozygous patients (11.2\% vs. $14.0 \%$;

Corresponding Author: Peter Nagele, MD, MSc, Dept of Anesthesiology, Washington University School of Medicine, 660 S. Euclid Ave, Box 8054, St. Louis, MO 63110, nagelep@wustl.edu; phone: 314-362-5129; fax: 314-362-1185.

\#VINO Study Team members are listed in Appendix 1.

Publisher's Disclaimer: This is a PDF file of an unedited manuscript that has been accepted for publication. As a service to our customers we are providing this early version of the manuscript. The manuscript will undergo copyediting, typesetting, and review of the resulting proof before it is published in its final citable form. Please note that during the production process errors may be discovered which could affect the content, and all legal disclaimers that apply to the journal pertain.

Conflicts of Interest:

Nagele: Roche Diagnostics US (Indianapolis, IN) provided us with free troponin assays and funds to cover the costs running these assays. No other conflicts of interest.

Brown and Francis: No conflicts of interest.

Scott: Research Support - Siemens Healthcare Diagnostic (Tarrytown, NY); Consulting - Roche Diabetes Care (Indianapolis, IN)

Gage and Miller: No conflicts of interest. 
relative risk $0.96,95 \%$ CI 0.85 to $1.07, \mathrm{p}=0.48$ ). B-vitamins blunted the rise in homocysteine, but had no effect on cardiac troponin I elevation compared to patients receiving placebo (13.2\% vs. $13.6 \%$; relative risk $1.02,95 \%$ CI 0.78 to $1.32, \mathrm{p}=0.91$ ).

Conclusions-Neither MTHFR C677T and A1298C gene variant nor acute homocysteine increase are associated with perioperative cardiac troponin elevation after nitrousoxide anesthesia. B-vitamins blunt nitrous oxide-induced homocysteine increase but have no effect on cardiac troponin elevation.

\section{Introduction}

In use for more than 150 years, nitrous oxide (laughing gas) is not only the oldest but also one of the most widely used general anesthetics worldwide. Due to its weak potency, nitrous oxide is typically used as an adjunct during general anesthesia at a concentration of 50-70\%. Its use during general anesthesia, particularly among patients with cardiac risk factors, has been associated with an increased risk for perioperative myocardial ischemia and infarction in some studies, ${ }^{1-3}$ but not others. ${ }^{4-8}$

Nitrous oxide causes an acute increase in plasma homocysteine by irreversible inactivation of vitamin $B_{12},{ }^{9-11}$ a side effect unrelated to its anesthetic action. ${ }^{12,13}$ The acute increase in homocysteine has been proposed as the cause for the increased perioperative myocardial infarction risk. ${ }^{14}$ Previously, we showed that patients homozygous for the C677T or A1298C variant in the MTHFR (methylenetetrahydrofolate reductase) gene, which is the most important genetic determinant of plasma homocysteine, ${ }^{15-19}$ developed higher plasma homocysteine concentrations after nitrous oxide anesthesia. ${ }^{20}$

The purpose of the present investigation was to determine whether patients who were homozygous for the MTHFR C677T or A1298C variant had an increased risk for perioperative cardiac events after nitrous oxide anesthesia and if this risk could be mitigated by B-vitamins which reliably lower plasma homocysteine. ${ }^{21-23}$ To answer this question, we conducted a double-blind, randomized placebo-controlled trial. In the trial, patients scheduled for nitrous oxide anesthesia were randomly allocated to receive B-vitamins or placebo.

\section{Materials and Methods}

\section{Study Design and Oversight}

The Vitamins in Nitrous Oxide (VINO) trial was a single-center randomized, double-blind placebo-controlled trial of nitrous oxide and B-vitamins in patients with or at risk for coronary artery disease undergoing non-cardiac surgery at Barnes-Jewish-Hospital, St. Louis. The investigators were responsible for all aspects of the trial including design, protocol, data collection and analyses. The study was conducted in accordance to the protocol. A data and safety monitoring board monitored the trial. The study was approved by the Washington University institutional review board (St. Louis, MO), and all patients provided written, informed consent. The trial was registered at clinicaltrials.gov with the identifier NCT00655980.

\section{Patients}

Adult patients diagnosed with or at risk for coronary artery disease (combination of at least two risk factors such as smoking history, hypertension, hypercholesterolemia, peripheral vascular disease, diabetes, stroke/transient ischemic attack) who were scheduled for elective non-cardiac surgery under general anesthesia lasting $>2$ hours were assessed for eligibility. Patients were ineligible if they had a contraindication to the use of nitrous oxide (e.g., 
pneumothorax, bowel obstruction, laparoscopic surgery, elevated intracranial pressure, middle ear occlusion); clinically significant pulmonary disease requiring supplemental oxygen; patients not expected to survive 24 hours; patients taking supplemental vitamin $\mathrm{B}_{12}$ or folic acid; allergy or hypersensitivity to cobalamins; Leber's disease or a seizure disorder.

\section{Randomization and Intervention}

The VINO trial consisted of two randomized arms with a total sample size of 500 patients who all received nitrous oxide throughout surgery at a concentration of $60 \%$. Patients were randomized to receive either $1 \mathrm{mg}$ vitamin $\mathrm{B}_{12}$ and $5 \mathrm{mg}$ folic acid (in $100 \mathrm{~mL}$ of normal saline) before and after surgery (nitrous oxide/B-vitamin group; $\mathrm{n}=250$ ) or a placebo infusion ( $100 \mathrm{~mL}$ normal saline; nitrous oxide/placebo group, $\mathrm{n}=250$ ). After initiation of the trial, the addition of a nitrous oxide-free non-randomized reference group $(n=125)$ was recommended during scientific review at the National Institutes of Health to determine if nitrous oxide had an effect on perioperative cardiac events independent of homocysteine elevation. Patients in this reference cohort were drawn from the same population, had identical inclusion and exclusion criteria but received nitrous oxide-free anesthesia and no B-vitamins. The protocol was amended and the first patient in the reference group was enrolled in May 2010 (around study midpoint). No changes to the primary and secondary study outcomes were made. Patients in the reference group received an identical intraoperative oxygen concentration ( $40 \%$ oxygen; $60 \%$ nitrogen). All other aspects of intraoperative management were at the discretion of the anesthesia team.

The B-vitamin/placebo-infusion was covered with aluminum foil by an independent clinical pharmacist to prevent unblinding. Randomization was performed by our clinical pharmacy service as well and was in blocks of random sizes using the Moses-Oakford algorithm ${ }^{24}$; no member of the study team had access to the randomization sequence until study enrolment finished. Patients, all members of the clinical care team (anesthesia team, surgeons, nurses), all members of the study team and outcome assessors were blinded to the group assignment and genotype which was determined after the patient had completed the study. Due to practical reasons, the administration of nitrous oxide was open label.

\section{Outcomes}

For outcome assessments, patients had five serial blood collections and electrocardiograms at the following time points: preoperative (baseline), end of surgery, postoperative days 1,2, and 3. Plasma total homocysteine (tHcy), serum troponin I (TnI; Siemens Dimension RxL, Siemens Tarrytown, NY) and high-sensitivity troponin T (hs-cTnT; Roche Elycsys 2010; Roche Diagnostics, Indianapolis, IN) were measured at all time points; serum folate and vitamin $\mathrm{B}_{12}$ were measured at baseline and on postoperative day 1. MTHFR genotypes (rs1801131, rs1801133) were determined by the Sequenom MassARRAY (Sequenom, San Diego, CA) system.

The primary study endpoint was the incidence of myocardial injury, as defined by cardiac troponin I (cTnI) elevation within the first 72 hours after surgery. Secondary endpoints were the incidence of myocardial infarction within the first 72 hours after surgery as well as a composite of 30-day mortality and non-fatal MI which were assessed by a 30-day follow-up interview and medical records review. For the assessment of the primary study outcome, a Food and Drug Administration-cleared troponin I assay was used (Siemens Dimension RxL; limit of detection: $0.04 \mu \mathrm{g} / \mathrm{L} ; 99^{\text {th }}$ percentile: $0.07 \mu \mathrm{g} / \mathrm{L} ; 10 \%$ coefficient of variation: 0.14 $\mu \mathrm{g} / \mathrm{L}){ }^{25}$ During the course of the trial, a novel high-sensitivity troponin $\mathrm{T}$ assay became available (Roche Elecsys, limit of detection: $5.0 \mathrm{ng} / \mathrm{L} ; 99^{\text {th }}$ percentile: $14 \mathrm{ng} / \mathrm{L} ; 10 \% \mathrm{CV}: 13$ $\mathrm{ng} / \mathrm{L})^{25}$, which we additionally used due to its markedly increased sensitivity in the detection of circulating troponins (currently not cleared by the US Food and Drug 
Administration). Cardiac troponin elevation was defined as a peak postoperative cardiac troponin I concentration $>99^{\text {th }}$ percentile $(>0.07 \mu \mathrm{g} / \mathrm{L})$. Myocardial infarction was defined according to the universal definition (troponin I elevation $>99^{\text {th }}$ percentile plus electrocardiogram changes indicative of myocardial ischemia and/or clinical symptoms). ${ }^{26}$ electrocardiograms were read and analyzed by an expert assessor blinded to the group assignment. Adverse events were assessed by the study team from patient medical records.

\section{Statistical Analysis}

Patients were grouped according to their MTHFR genotype in homozygotes (MTHFR 677TT and 1298CC) and wild-type/heterozygotes (MTHFR 677CC and CT, and 1298AA and AC) based on our previous observation suggesting a significantly increased homocysteine increase after nitrous oxide anesthesia among MTHFR homozygous patients. ${ }^{20}$ The sample size determination was planned for the two randomized trial arms and did not include the reference group. Extrapolated from incidences observed in patients undergoing vascular surgery and our previous study, ${ }^{20}$ we expected an incidence rate of cardiac troponin elevations among MTHFR homozygous patients (expected proportion $20 \%$ of the study population) of $24 \%$ (with B-vitamins) and $47 \%$ (placebo) and at $20 \%$ for non-homozygous patients (B-vitamins) and 32\% (placebo).

Based on these assumptions, a sample size of $n=500$ was sufficient to detect a statistically significant difference between MTHFR homozygotes with an $\alpha=0.05$ and $\beta=0.30$ and between MTHFR non-homozygotes with an $\alpha=0.05$ and $\beta=0.22$. Using continuous data, we could detect at a power of 0.7 a difference of 0.5 of a standard deviation between MTHFR homozygotes and a difference of 0.28 standard deviations between non-homozygotes. All power calculations are based on 2-tail tests, with a .05 significance level using the program STPLAN (MD Anderson Cancer Center, University of Texas, Houston TX).

Data were entered into a REDCap data base ${ }^{27}$ and exported into SAS (Cary, NC). Descriptive statistics for each group were computed including the calculation of the median and 25th and 75th percentiles since many of the distributions were skewed or means \pm SD. When analyzing dichotomous outcomes, chi-square tests and logistic regression were used. For continuous values which were obtained at multiple time points, a repeated measures analysis of variance was computed and appropriate contrasts from the time*group effect constructed to compare changes from baseline to peak values between groups. Analyses were also repeated using stratification by MTHFR genotype. Where regression diagnostics raised concerns, results were confirmed using transformations (e.g. logarithmic) or rank order transformations. Significance level was set at 0.05, 2-tailed.

\section{Results}

From March 2008 to December 2011 we enrolled 687 patients into the study; 62 patients were withdrawn after randomization but before surgery resulting in a final intention-to-treat sample of 625 patients. The most common causes for withdrawal were cancelled surgeries or refusal by the anesthesia team (Figure 1). Of the final study sample, 250 patients were randomly assigned to the nitrous oxide/B-vitamin group (5 patients did not receive nitrous oxide), and 250 to the nitrous oxide group/placebo (three patients did not receive nitrous oxide). 125 were assigned to the non-randomized reference group. Baseline characteristics between the two randomized study arms were well balanced (Table 1). The MTHFR A1298C allele (minor allele frequency 0.29) was in Hardy-Weinberg equilibrium, but the C677T allele (minor allele frequency 0.28) was not: the TT variant had an observed prevalence of: $10.6 \%$ (expected: $7.8 \%$; $\mathrm{p}<0.001$ ). 


\section{Study Outcomes - Homocysteine}

Patients in the nitrous oxide/B-vitamin group and nitrous oxide/placebo group had similar median exposures to nitrous oxide (measured as the product of duration of nitrous oxide anesthesia in hours and fraction of inspiratory nitrous oxide concentration): $1.7 \pm 1.0$ percent*hours vs. $1.7 \pm 1.0$ percent*hours $(\mathrm{p}=0.62)$. Patients in the nitrous oxide/B-vitamin group had significantly higher postoperative vitamin $\mathrm{B}_{12}$ and folate concentrations compared to baseline and to both other groups (Supplemental Digital Content 1). Plasma total homocysteine concentrations rose in all patients who received nitrous oxide but the increase was significantly blunted in the group receiving B-vitamins, both for patients homozygous for either MTHFR allele (677TT, 1298CC) and wild-type and heterozygous (Figure 2, Table 2). The MTHFR C677T and A1298C allele status did not influence the extent of plasma total homocysteine increase: In the B-vitamin group homozygous patients had a median increase of $2.1 \mu \mathrm{mol} / \mathrm{L}$ [IQR 0 to 5.3] and wild-type/heterozygous $2.1 \mu \mathrm{mol} / \mathrm{L}$ [ -0.2 to 5.5$]$; in the placebo group homozygous patients had $3.1 \mu \mathrm{mol} / \mathrm{L}$ [IQR 1.4 to 7.3 ] increase compared to 3.8 [IQR 0.6 to 6.8 ] for wild-type/heterozygous patients.

\section{Influence of MTHFR genotype on perioperative cardiac events}

Among the 500 patients within the randomized trial, neither the MTHFR genotype nor the B-vitamin treatment had an effect on cardiac study outcomes. Patients who were homozygous for the MTHFR C677T or A1298C gene variant ( $\mathrm{n}=98 ; 19.6 \%$ ) had an $11.2 \%$ incidence rate of postoperative cTnI elevation compared to $14.0 \%$ for wild-type and heterozygous patients (RR $0.96,95 \%$ CI 0.85 to $1.07, \mathrm{p}=0.48$; Table 3 ). B-vitamins had no effect on cTnI elevation compared to patients receiving placebo (13.2\% vs. 13.6\%; RR 1.02, $95 \%$ CI 0.78 to $1.32, \mathrm{p}=0.91$ ), regardless of MTHFR genotype.

Patients who were homozygous for the MTHFR C677T or A1298C gene variant had a 3.1\% incidence rate of perioperative myocardial infarction (within 3 days after surgery) compared to $4.7 \%$ for wild-type and heterozygous patients (RR 0.93 ; $95 \%$ CI 0.78 to $1.10 ; \mathrm{p}=0.48$ ). The incidence of postoperative myocardial infarction was $6.0 \%$ in the nitrous oxide/placebo group and $2.8 \%$ in the nitrous oxide/B-vitamin group (RR 1.60; 95\% CI 0.87 to 2.98 , $\mathrm{p}=0.09$ ).

The extent of myocardial injury or necrosis as indicated by the rise in high-sensitivity troponin $\mathrm{T}(\Delta \mathrm{hs}-\mathrm{cTnT})$, was not different among MTHFR homozygous and wild-type/ heterozygous patients and patients who received B-vitamins or placebo (Table 2 and Figure $3)$.

Acute homocysteine increase was not correlated with cardiac troponin release as indicated by the rise in hs-cTnT ( $\Delta$ hs-cTnT) (Spearman's correlation coefficient $=0.003, \mathrm{p}=0.94)$. At 30 days, no patient had died in the B-vitamin group and three in the nitrous oxide group $(1.2 \%)$.

Non-randomized nitrous oxide-free reference group-In addition to the randomized trial cohort, an additional, non-randomized reference group $(n=125)$ of patients receiving nitrous oxide-free anesthesia was enrolled. Nine patients inadvertently received nitrous oxide during emergence from anesthesia; four patients for the duration of the case. The baseline characteristics of the nitrous oxide-free reference group were very similar to the randomized cohort (See table, Supplemental Digital Content 2). Patients in the nitrous oxide-free reference group had similar incidence rates of cardiac troponin I elevation (13.6\% vs. $13.4 \%)$ and a slightly increased rate of myocardial infarction (6.4\% vs. $4.4 \%)$. The median $\Delta$ hs-cTnT was similar to the randomized cohort, indicative of a similar magnitude of 
perioperative myocardial injury between patients receiving nitrous oxide and nitrous oxidefree anesthesia (See table, Supplemental Digital Content 3-4).

\section{Safety}

No adverse events were related to the administration of intravenous B-vitamins (Table 4). Within the first three postoperative days, 16 patients $(6.4 \%)$ in the nitrous oxide/B-vitamin group had a cardiovascular event compared to $25(10.0 \%)$ in the nitrous oxide/placebo group (Table 4 and Supplemental Digital Content 5).

\section{Discussion}

This trial resulted in several findings: First, the prophylactic use of vitamin $\mathrm{B}_{12}$ and folic acid successfully blunted the nitrous oxide-induced increase in plasma homocysteine, but had no effect on perioperative cardiac outcomes. Second, patients who are homozygous for the MTHFR C677T and A1298C gene variants had no increased risk for perioperative cardiac events after nitrous oxide anesthesia. Third, the acute increase in plasma homocysteine caused by nitrous oxide was not associated with perioperative cardiac troponin elevations.

Several points deserve comment. Consistent with prior evidence, ${ }^{9}$ our study showed that nitrous oxide causes an acute increase in plasma homocysteine that lasts several days. Contrary to previous suggestions, however, the observed plasma homocysteine increase was not associated with troponin elevations or myocardial infarction. The administration of Bvitamins before and after nitrous oxide anesthesia clearly lowered plasma homocysteine levels, but did not decrease the rate and magnitude of postoperative cardiac troponin increase or myocardial infarction. We therefore question the notion that acute nitrous oxideinduced hyperhomocysteinemia has a causal effect on perioperative myocardial ischemia and infarction. There is now emerging consensus that homocysteine may be a marker rather than a cause of atherosclerotic disease and increased cardiovascular risk, ${ }^{23,28,29}$ despite impressive associations between chronically elevated homocysteine and coronary artery disease. ${ }^{30,31}$

To our surprise and contrary to our previous work, the MTHFR C677T and A1298C genotype had no influence on nitrous oxide-induced homocysteine increase. ${ }^{20}$ A likely explanation for this lack of influence lies in the mandatory dietary folate fortification of all grain products in the United States, which has increased folate levels throughout the population. ${ }^{32}$ Dietary folate fortification also reduces the effects of the MTHFR polymorphisms. ${ }^{19,33}$ Our previous study was conducted in Austria, a country without mandatory folate fortification, which may explain why we previously observed a significant effect of MTHFR polymorphisms on nitrous oxide-induced homocysteine concentrations.

Previous research provides conflicting evidence regarding nitrous oxide and perioperative myocardial ischemia and infarction. Several smaller studies in high-risk patients observed no effect of nitrous oxide on myocardial ischemia, ${ }^{4-6}$ whereas a recent study showed an increased risk for ischemic electrocardiogram changes; ${ }^{1}$ however, in this latter study no cardiac biomarkers or clinical outcomes were reported. The only large clinical trial investigating nitrous oxide and cardiovascular outcomes, the ENIGMA trial, reported an inconclusive, statistically non-significant increase in the incidence of myocardial infarction from $0.7 \%(\mathrm{n}=7 / 997)$ to $1.3 \%(\mathrm{n}=13 / 1015$, OR $0.54,95 \%$ CI $0.22-1.37, \mathrm{p}=0.2)$ in patients receiving nitrous oxide. ${ }^{2}$ Nevertheless, since the publication of these studies many practitioners have abandoned the use of nitrous oxide for patients with cardiac risk factors. Our study suggests that there is no increased cardiac risk from acute nitrous oxide-induced hyperhomocysteinemia. The ongoing ENIGMA-II trial, a large scale multicenter clinical 
trial, will provide robust and definitive evidence in the question of nitrous oxide and perioperative myocardial infarction. ${ }^{34}$

In addition to a standard Food and Drug Administration-cleared troponin I assay, our study used a novel high-sensitivity troponin $\mathrm{T}$ assay to detect myocardial necrosis and infarction. High-sensitivity troponin assays allow the detection of circulating cardiac troponins at extremely low levels (ng/L) allowing for the calculation of a relative change $\Delta \mathrm{hs}-\mathrm{cTnT}$ compared to baseline within each patient. ${ }^{35}$ In our study, more than $80 \%$ of patients had a measurable rise in postoperative high-sensitivity troponin $\mathrm{T}$ compared to baseline. Our data suggest that high-sensitivity troponin assays may be the most sensitive method for the detection of perioperative myocardial injury and infarction.

The study has several limitations. First, the observed event rate of cardiac troponin I elevations was substantially lower than expected. In hindsight, expecting an event rate of 47\% among patients homozygous for either MTHFR variant who received nitrous oxide, was probably overly optimistic and resulted in a lower than expected study power. Given the remarkably negative results both in the incidence rates between the groups and the extent of myocardial injury as indicated by the nearly identical change in high-sensitivity troponin $\mathrm{T}$, we doubt that a larger sample size would have resulted in a different study outcome.

Second, because our study was conducted in a country with dietary folate fortification, it is possible that its findings may not be generalizable to regions that do not have dietary folate fortification. Third, in the United States many adults use over-the counter multivitamins and we cannot rule out that some patients self-medicated multivitamins within the first days after surgery which could have affected plasma homocysteine concentrations and, theoretically, study outcomes.

In summary, the findings of this trial suggest that neither nitrous oxide-induced acute hyperhomocysteinemia nor MTHFR genotype is associated with perioperative cardiac troponin elevation after nitrous oxide anesthesia. The prophylactic use of B-vitamins is efficacious in blunting nitrous oxide-induced homocysteine increase but has no effect on perioperative cardiac events. We therefore believe that, based on current evidence, practitioners who feel that nitrous oxide could be beneficial for their patients should not refrain from administering it based on concern for acute homocysteine increase or MTHFR gene variant.

\section{Supplementary Material}

Refer to Web version on PubMed Central for supplementary material.

\section{Acknowledgments}

We would like to thank all faculty members, residents and CRNAs at Barnes-Jewish Hospital (St. Louis, MO) who supported the VINO trial, most importantly to Alex S. Evers, MD, Henry Mallinckrodt Professor of Anesthesiology and Chairman, Dept. of Anesthesiology, Washington University, without whose support the VINO trial would have been impossible to conduct. A special thanks to Kathryn Vehe, PharmD, from the Investigational Pharmacy, Barnes-Jewish Hospital for her strong support. We also would like to thank Ningying Wu, PhD, (Division of Biostatistics, Washington University School of Medicine) for her help during the statistical analysis and Barbara Zehnbauer, PhD, Professor of Pathology and Immunology and Medical Director, Molecular Diagnostics Laboratory, Washington University School of Medicine; now: Branch Chief and Senior Service Fellow, Centers for Disease Control and Prevention, Atlanta, GA) for her help in planning the genetic analysis. Most importantly, we would like to thank Evan D. Kharasch, MD, PhD, Russell D. and Mary B. Shelden Professor of Anesthesiology, Director of the Division of Clinical and Translational Research in the Department of Anesthesiology and Vice Chancellor for Research at Washington University in St. Louis for his outstanding mentorship and his invaluable advice and support in planning, execution and publication of the VINO trial. 
This work was received from the Division of Clinical and Translational Research, Department of Anesthesiology, Washington University School of Medicine.

Funding/Support:

The VINO trial was funded by a grant from the National Institute for General Medical Sciences(K23 GM087534), National Institutes of Health (Bethesda, MD) and a grant to Washington University Institute of Clinical and Translational Sciences (UL1RR024992), by a mentored research training grant from the Foundation for Anesthesia Education and Research (FAER, Rochester, MN) to PN, and the Division of Clinical and Translational Research, Department of Anesthesiology, Washington University, as well as Roche Diagnostics (Indianapolis, IN).

Role of the funding sources:

Roche Diagnostics provided high-sensitivity troponin $\mathrm{T}$ assays and funding to cover the costs of running these assays, but had no role in the design of the study, data collection or analysis or manuscript preparation and submission. The other funders/sponsors had no role in the collection, management, analysis, and interpretation of the data; or preparation, review, or approval of the manuscript.

\section{Appendix 1}

\section{VINO study team}

Peter Nagele, M.D., M.Sc., Assistant Professor,

Frank Brown, B.Sc., Research Coordinator

Amber Francis, B.S.N, R.N., Research Coordinator

Joshua Johnston, M.D., Resident,

Lesley K. Rao, M.D., Instructor,

Jane Blood, R.N., Research Nurse Supervisor,

Konrad Meissner, M.D., Instructor

Anson Liu, B.Sc., Graduate Research Assistant

Olumuyiwa Idowu, Undergraduate Research Assistant,

Samantha Morley, B.Sc., Undergraduate Research Assistant,

Kenji Kobayashi, Undergraduate Research Assistant,

\section{All Division of Clinical and Translational Research, Department of Anesthesiology}

Mitchell Scott, Ph.D., Professor, Department of Pathology \& Immunology

Brian F. Gage, M.D., M.Sc., Professor, Division of General Medical Sciences, Department of Internal Medicine

Lisa de las Fuentes, M.D., Assistant Professor, Cardiovascular Division, Dept. of Internal Medicine

J. Philip Miller, A.B., Professor, Division of Biostatistics

All, Washington University School of Medicine, St. Louis, MO. 


\section{References}

1. Badner NH, Beattie WS, Freeman D, Spence JD. Nitrous oxide-induced increased homocysteine concentrations are associated with increased postoperative myocardial ischemia in patients undergoing carotid endarterectomy. Anesth Analg. 2000; 91:1073-1079. [PubMed: 11049886]

2. Myles PS, Leslie K, Chan MT, Forbes A, Paech MJ, Peyton P, Silbert BS, Pascoe E, Group ET. Avoidance of nitrous oxide for patients undergoing major surgery: A randomized controlled trial. Anesthesiology. 2007; 107:221-231. [PubMed: 17667565]

3. Leslie K, Myles PS, Chan MT, Forbes A, Paech MJ, Peyton P, Silbert BS, Williamson E. Nitrous oxide and long-term morbidity and mortality in the ENIGMA trial. Anesth Analg. 2011; 112:387393. [PubMed: 20861416]

4. Cahalan MK, Prakash O, Rulf EN, Cahalan MT, Mayala AP, Lurz FC, Rosseel P, Lachitjaran E, Siphanto K, Gussenhoven EJ, Roelandt JRTC. Addition of nitrous oxide to fentanyl anesthesia does not induce myocardial ischemia in patients with ischemic heart disease. Anesthesiology. 1987; 67:925-929. [PubMed: 3688536]

5. Kozmary SV, Lampe GH, Benefiel D, Cahalan MK, Wauk LZ, Whitendale P, Schiller NB, Eger EI. No Finding of Increased Myocardial-Ischemia during or after Carotid Endarterectomy under Anesthesia with Nitrous-Oxide. Anesth Analg. 1990; 71:591-596. [PubMed: 2240629]

6. Mitchell MM, Prakash O, Rulf EN, van Daele ME, Cahalan MK, Roelandt JR. Nitrous oxide does not induce myocardial ischemia in patients with ischemic heart disease and poor ventricular function. Anesthesiology. 1989; 71:526-534. [PubMed: 2802210]

7. Sanders RD, Graham C, Lewis SC, Bodenham A, Gough MJ, Warlow C. Gala Trial Investigators. Nitrous oxide exposure does not seem to be associated with increased mortality, stroke, and myocardial infarction: A non-randomized subgroup analysis of the General Anaesthesia compared with Local Anaesthesia for carotid surgery (GALA) trial. Br J Anaesth. 2012; 109:361-367. [PubMed: 22710267]

8. Turan A, Mascha EJ, You J, Kurz A, Shiba A, Saager L, Sessler DI. The Association Between Nitrous Oxide and Postoperative Mortality and Morbidity After Noncardiac Surgery. Anesth Analg. 2012 published online July 19, 2012.

9. Badner NH, Drader K, Freeman D, Spence JD. The use of intraoperative nitrous oxide leads to postoperative increases in plasma homocysteine. Anesth Analg. 1998; 87:711-713. [PubMed: 9728858]

10. Kondo H, Osborne ML, Kolhouse JF, Binder MJ, Podell ER, Utley CS, Abrams RS, Allen RH. Nitrous oxide has multiple deleterious effects on cobalamin metabolism and causes decreases in activities of both mammalian cobalamin-dependent enzymes in rats. J Clin Invest. 1981; 67:12701283. [PubMed: 6112240]

11. Amess JA, Burman JF, Rees GM, Nancekievill DG, Mollin DL. Megaloblastic haemopoiesis in patients receiving nitrous oxide. Lancet. 1978; 2:339-342. [PubMed: 79709]

12. Jevtovic-Todorovic V, Todorovic SM, Mennerick S, Powell S, Dikranian K, Benshoff N, Zorumski CF, Olney JW. Nitrous oxide (laughing gas) is an NMDA antagonist, neuroprotectant and neurotoxin. Nat Med. 1998; 4:460-463. [PubMed: 9546794]

13. Nagele P, Metz LB, Crowder CM. Nitrous oxide $(\mathrm{N}(2) \mathrm{O})$ requires the N-methyl-D-aspartate receptor for its action in Caenorhabditis elegans. Proc Natl Acad Sci U S A. 2004; 101:8791-8796. [PubMed: 15159532]

14. Myles PS, Leslie K, Silbert B, Paech MJ, Peyton P. A review of the risks and benefits of nitrous oxide in current anaesthetic practice. Anaesth Intensive Care. 2004; 32:165-172. [PubMed: 15957712]

15. Kang SS, Passen EL, Ruggie N, Wong PW, Sora H. Thermolabile defect of methylenetetrahydrofolate reductase in coronary artery disease. Circulation. 1993; 88:1463-1469. [PubMed: 8403293]

16. Frosst P, Blom HJ, Milos R, Goyette P, Sheppard CA, Matthews RG, Boers GJ, den Heijer M, Kluijtmans LA, van den Heuvel LP, Rozen R. A candidate genetic risk factor for vascular disease: A common mutation in methylenetetrahydrofolate reductase. Nat Genet. 1995; 10:111-113. [PubMed: 7647779] 
17. Ueland PM, Hustad S, Schneede J, Refsum H, Vollset SE. Biological and clinical implications of the MTHFR C677T polymorphism. Trends Pharmacol Sci. 2001; 22:195-201. [PubMed: 11282420]

18. Bathum L, Petersen I, Christiansen L, Konieczna A, Sorensen TI, Kyvik KO. Genetic and environmental influences on plasma homocysteine: Results from a Danish twin study. Clin Chem. 2007; 53:971-979. [PubMed: 17412799]

19. Nagele P, Meissner K, Francis A, Fodinger M, Saccone NL. Genetic and environmental determinants of plasma total homocysteine levels: Impact of population-wide folate fortification. Pharmacogenet Genomics. 2011; 21:426-431. [PubMed: 21597397]

20. Nagele P, Zeugswetter B, Wiener C, Burger H, Hupfl M, Mittlbock M, Fodinger M. Influence of methylenetetrahydrofolate reductase gene polymorphisms on homocysteine concentrations after nitrous oxide anesthesia. Anesthesiology. 2008; 109:36-43. [PubMed: 18580170]

21. Albert CM, Cook NR, Gaziano JM, Zaharris E, MacFadyen J, Danielson E, Buring JE, Manson JE. Effect of folic acid and B vitamins on risk of cardiovascular events and total mortality among women at high risk for cardiovascular disease: A randomized trial. JAMA. 2008; 299:2027-2036. [PubMed: 18460663]

22. Armitage JM, Bowman L, Clarke RJ, Wallendszus K, Bulbulia R, Rahimi K, Haynes R, Parish S, Sleight P, Peto R, Collins R. Study of the Effectiveness of Additional Reductions in C; Homocysteine Collaborative G. Effects of homocysteine-lowering with folic acid plus vitamin B12 vs placebo on mortality and major morbidity in myocardial infarction survivors: A randomized trial. JAMA. 2010; 303:2486-2494. [PubMed: 20571015]

23. Lonn E, Yusuf S, Arnold MJ, Sheridan P, Pogue J, Micks M, McQueen MJ, Probstfield J, Fodor G, Held C, Genest J Jr. Heart Outcomes Prevention Evaluation I. Homocysteine lowering with folic acid and B vitamins in vascular disease. N Engl J Med. 2006; 354:1567-1577. [PubMed: 16531613]

24. Meinert, CL. Clinical Trials: Design, Conduct, and Analysis. New York: Oxford University Press; 1986.

25. Apple FS, Collinson PO. IFCC Task Force on Clinical Applications of Cardiac Biomarkers: Analytical characteristics of high-sensitivity cardiac troponin assays. Clin Chem. 2012; 58:54-61. [PubMed: 21965555]

26. Thygesen K, Alpert JS, White HD. ESC/ACCF/AHA/WHF Task Force for the Redefinition of Myocardial Infarction: Universal definition of myocardial infarction. Circulation. 2007; 116:26342653. [PubMed: 17951284]

27. Harris PA, Taylor R, Thielke R, Payne J, Gonzalez N, Conde JG. Research electronic data capture (REDCap)--a metadata-driven methodology and workflow process for providing translational research informatics support. J Biomed Inform. 2009; 42:377-381. [PubMed: 18929686]

28. Bonaa KH, Njolstad I, Ueland PM, Schirmer H, Tverdal A, Steigen T, Wang H, Nordrehaug JE, Arnesen E, Rasmussen K, Investigators NT. Homocysteine lowering and cardiovascular events after acute myocardial infarction. N Engl J Med. 2006; 354:1578-1588. [PubMed: 16531614]

29. Clarke R, Halsey J, Lewington S, Lonn E, Armitage J, Manson JE, Bonaa KH, Spence JD, Nygard O, Jamison R, Gaziano JM, Guarino P, Bennett D, Mir F, Peto R, Collins R. Collaboration BVTT: Effects of lowering homocysteine levels with $\mathrm{B}$ vitamins on cardiovascular disease, cancer, and cause-specific mortality: Meta-analysis of 8 randomized trials involving 37485 individuals. Arch Intern Med. 2010; 170:1622-1631. [PubMed: 20937919]

30. Chambers JC, Obeid OA, Refsum H, Ueland P, Hackett D, Hooper J, Turner RM, Thompson SG, Kooner JS. Plasma homocysteine concentrations and risk of coronary heart disease in UK Indian Asian and European men. Lancet. 2000; 355:523-527. [PubMed: 10683001]

31. Nygard O, Nordrehaug JE, Refsum H, Ueland PM, Farstad M, Vollset SE. Plasma homocysteine levels and mortality in patients with coronary artery disease. N Engl J Med. 1997; 337:230-236. [PubMed: 9227928]

32. Jacques PF, Selhub J, Bostom AG, Wilson PW, Rosenberg IH. The effect of folic acid fortification on plasma folate and total homocysteine concentrations. N Engl J Med. 1999; 340:1449-1454. [PubMed: 10320382] 
33. Holmes MV, Newcombe P, Hubacek JA, Sofat R, Ricketts SL, Cooper J, Breteler MMB, Bautista LE, Sharma P, Whittaker JC, Smeeth L, Fowkes FGR, Algra A, Shmeleva V, Szolnoki Z, Roest M, Linnebank M, Zacho J, Nalls MA, Singleton AB, Ferrucci L, Hardy J, Worrall BB, Rich SS, Matarin M, Norman PE, Flicker L, Almeida OP, van Bockxmeer FM, Shimokata H, Khaw KT, Wareham NJ, Bobak M, Sterne JAC, Smith GD, Talmud PJ, van Duijn C, Humphries SE, Price JF, Ebrahim S, Lawlor DA, Hankey GJ, Meschia JF, Sandhu MS, Hingorani AD, Casas JP. Effect modification by population dietary folate on the association between MTHFR genotype, homocysteine, and stroke risk: A meta-analysis of genetic studies and randomised trials. Lancet. 2011; 378:584-594. [PubMed: 21803414]

34. Myles PS, Leslie K, Peyton P, Paech M, Forbes A, Chan MT, Sessler D, Devereaux PJ, Silbert BS, Jamrozik K, Beattie S, Badner N, Tomlinson J, Wallace S, Group AT. Nitrous oxide and perioperative cardiac morbidity (ENIGMA-II) Trial: Rationale and design. Am Heart J. 2009; 157:488-494. e1. [PubMed: 19249419]

35. Kavsak PA, Walsh M, Srinathan S, Thorlacius L, Buse GL, Botto F, Pettit S, McQueen MJ, Hill SA, Thomas S, Mrkobrada M, Alonso-Coello P, Berwanger O, Biccard BM, Cembrowski G, Chan MT, Chow CK, de Miguel A, Garcia M, Graham MM, Jacka MJ, Kueh JH, Li SC, Lit LC, Martinez-Bru C, Naidoo P, Nagele P, Pearse RM, Rodseth RN, Sessler DI, Sigamani A, Szczeklik W, Tiboni M, Villar JC, Wang CY, Xavier D, Devereaux PJ. High sensitivity troponin T concentrations in patients undergoing noncardiac surgery: A prospective cohort study. Clin Biochem. 2011; 44:1021-1024. [PubMed: 21640092] 


\section{Summary Statement}

Neither MTHFR gene variants nor acute homocysteine increase are associated with perioperative cardiac troponin elevation after nitrous oxide anesthesia. B-vitamins blunt nitrous oxide-induced homocysteine increase but have no effect on cardiac troponin elevation. 


\section{FINAL BOX SUMMARY}

\section{What we already know about this topic}

- Nitrous oxide increases circulating homocysteine concentration, and may do so more in patients with variants of the MTHFR gene

- Whether patients with these variants have increased cardiac risk from nitrous oxide exposure and whether this can be mitigated by vitamin B12 administration are not known

\section{What this article tells us that is new}

- In 500 patients with cardiac risk factors undergoing noncardiac surgery with nitrous oxide, MTHFR gene variant did not alter homocysteine concentration or the incidence of cardiac injury

- Vitamin B12, although decreasing homocysteine concentration, did not alter the incidence of cardiac injury 


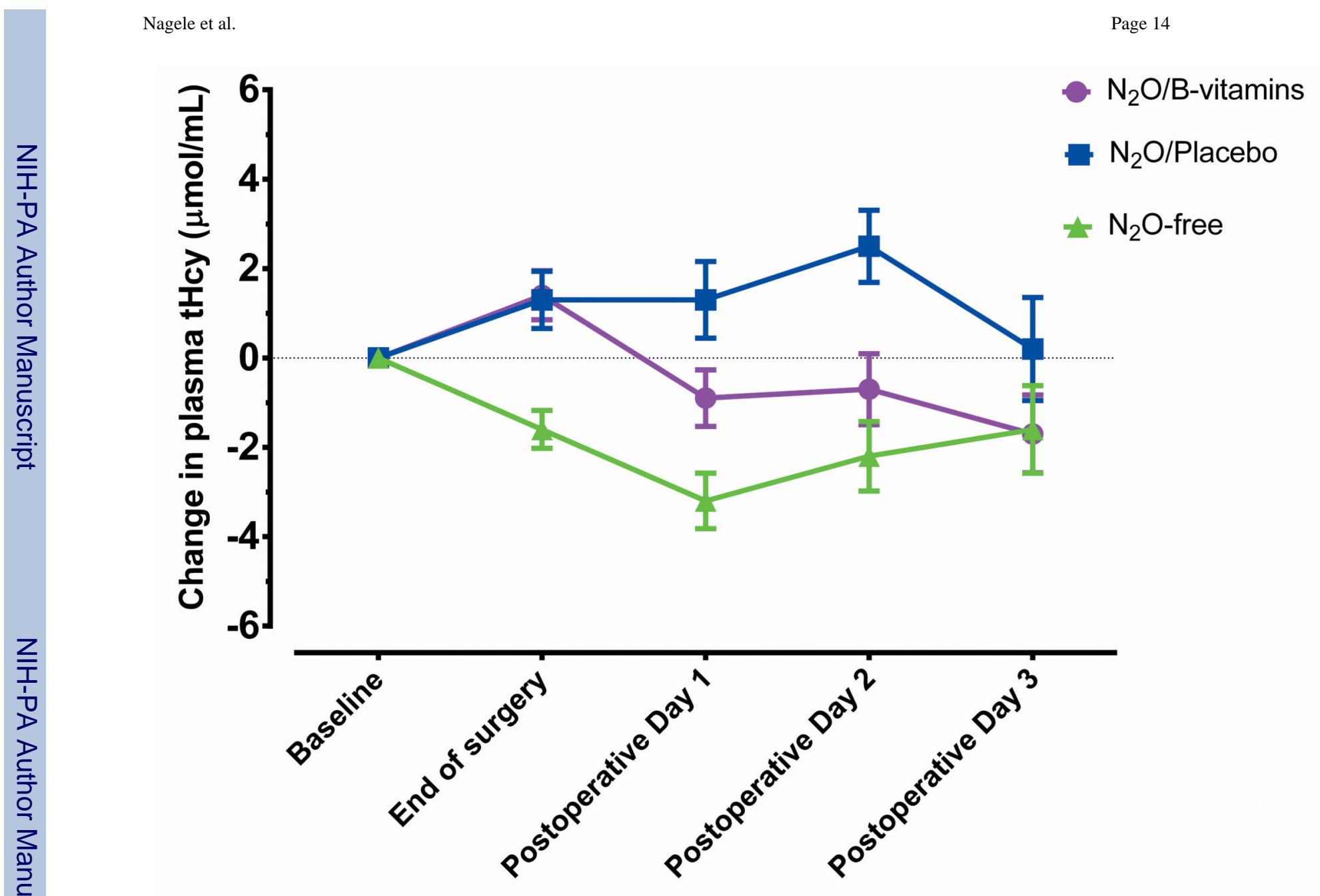

Fig 1. 


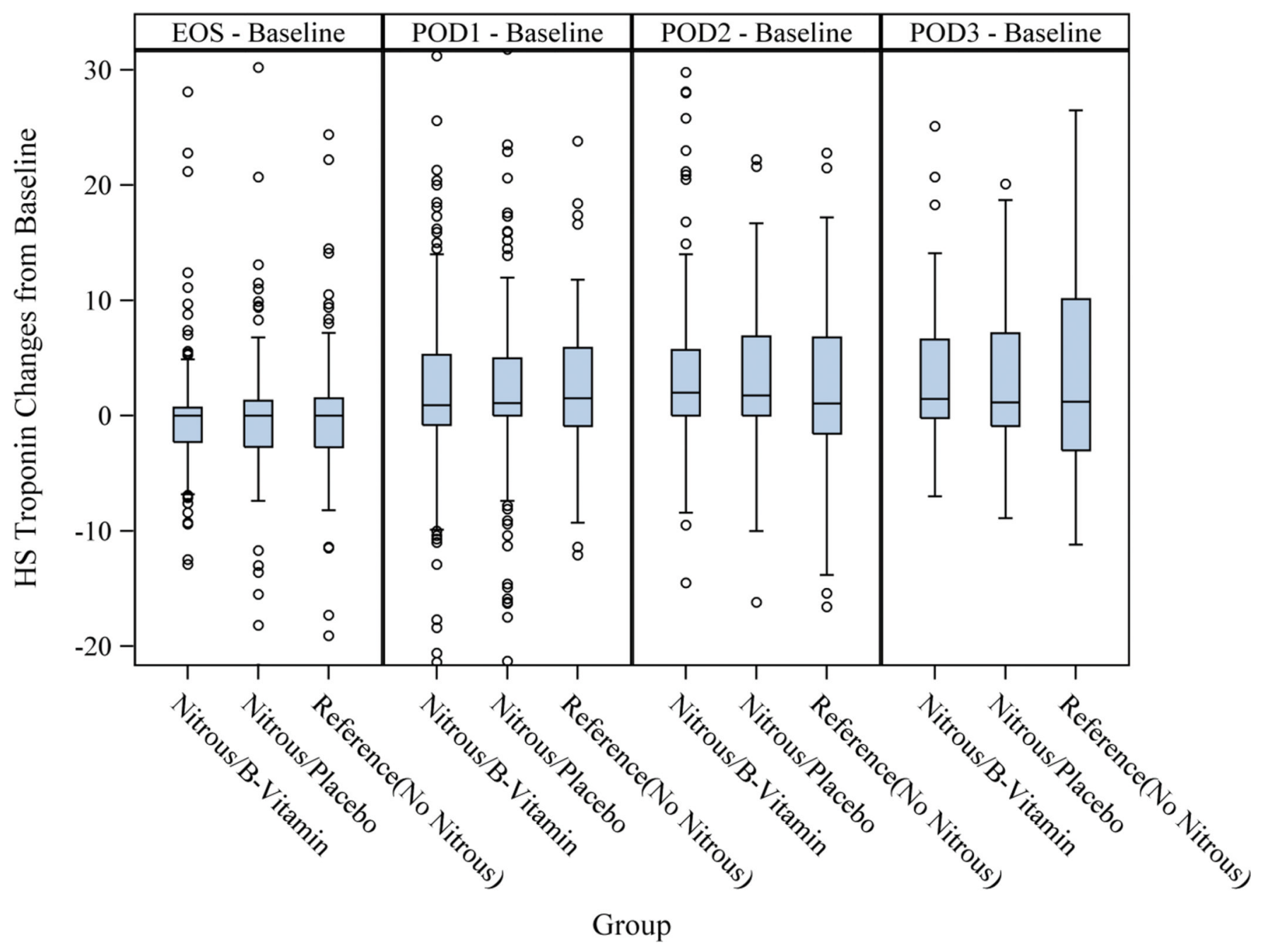

Fig 2. 


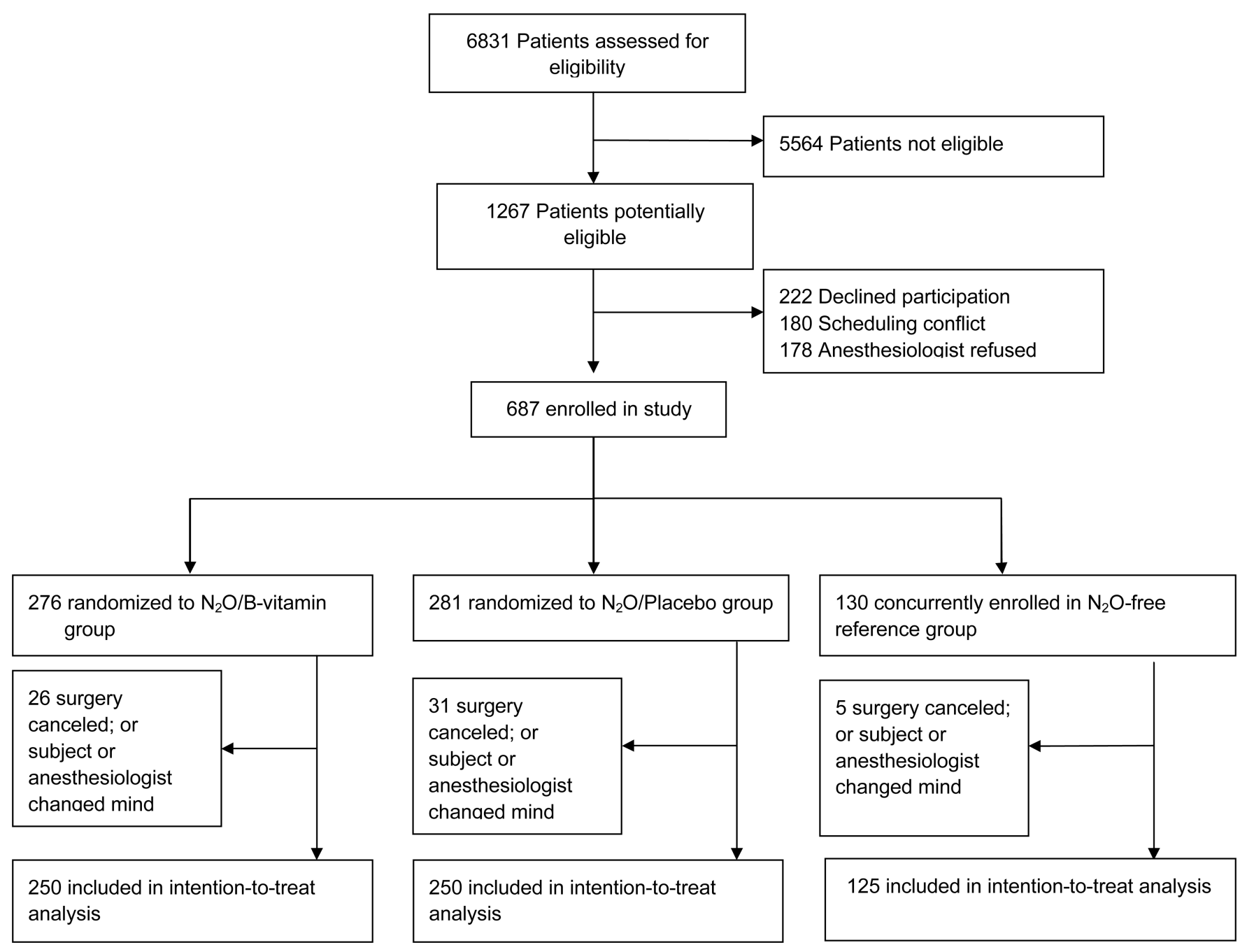

Fig 3. 
Table 1

Baseline Characteristics

\begin{tabular}{|c|c|c|}
\hline & $\begin{array}{c}\text { Nitrous Oxide/B- } \\
\quad \begin{array}{l}\text { Vitamins } \\
(\mathbf{n}=250)\end{array}\end{array}$ & $\begin{array}{c}\text { Nitrous Oxide } \\
\text { /Placebo } \\
(\mathbf{n}=\mathbf{2 5 0})\end{array}$ \\
\hline Mean age - yr & $64.7 \pm 10.6$ & $65.2 \pm 10.7$ \\
\hline Mean weight - $\mathrm{kg}$ & $90.3 \pm 22.7$ & $88.9 \pm 20.8$ \\
\hline Female Sex - no. (\%) & $92(36.8 \%)$ & $97(39.0 \%)$ \\
\hline \multicolumn{3}{|l|}{ Race - no. $(\%)$} \\
\hline White & $197(79.1 \%)$ & $200(80.0 \%)$ \\
\hline Black & $51(20.5 \%)$ & $49(19.6 \%)$ \\
\hline Other & $1(0.4 \%)$ & $1(0.4 \%)$ \\
\hline Smoking history - no. $(\%)$ & $195(79.0 \%)$ & $175(70.0 \%)$ \\
\hline Diabetes - no. (\%) & $96(38.6 \%)$ & $88(35.5 \%)$ \\
\hline Hypertension - no. (\%) & $200(80.0 \%)$ & $204(81.6 \%)$ \\
\hline Chronic renal failure - no. $(\%)$ & $16(6.5 \%)$ & $35(14.1 \%)$ \\
\hline On hemodialysis - no. (\%) & $1(0.4 \%)$ & $3(1.2 \%)$ \\
\hline Coronary artery disease - no. $(\%)$ & $140(56.0 \%)$ & $148(59.2 \%)$ \\
\hline Congestive heart failure - no. $(\%)$ & $27(10.8 \%)$ & $31(12.4 \%)$ \\
\hline Peripheral vascular disease - no. (\%) & $81(32.5 \%)$ & $85(34.4 \%)$ \\
\hline \multicolumn{3}{|l|}{ ASA status - no. $(\%)$} \\
\hline I & $1(0.4 \%)$ & 0 \\
\hline II & $45(18.0 \%)$ & $42(16.9 \%)$ \\
\hline III & $199(79.6 \%)$ & $196(79.0 \%)$ \\
\hline IV & $5(2.0 \%)$ & $10(4.0 \%)$ \\
\hline Lee's revised cardiac risk index (mean) & $1.9 \pm 0.8$ & $2.0 \pm 0.9$ \\
\hline Median serum vitamin $\mathrm{B}_{12} \mathrm{pg} / \mathrm{mL}$ (IQR) & $415(317-581)$ & $405(300-564)$ \\
\hline Median serum folate ng/mL (IQR) & $16.1(12.1-23.7)$ & $16.5(13.2-25.4)$ \\
\hline Mean plasma total homocysteine $\mu \mathrm{mol} / \mathrm{L}$ & $13.5 \pm 5.7$ & $13.4 \pm 5.8$ \\
\hline Median serum high-sensitivity troponin $\mathrm{T}$ ng/L (IQR) & $11.9(7.8-18.2)$ & $11.5(8.4-19.6)$ \\
\hline \multicolumn{3}{|l|}{ MTHFR C677T (rs1801133) } \\
\hline $677 \mathrm{CC}$ & $137(56.6 \%)$ & $130(53.1 \%)$ \\
\hline $677 \mathrm{CT}$ & $76(31.4 \%)$ & $89(36.3 \%)$ \\
\hline $677 \mathrm{TT}$ & $29(12.0 \%)$ & $26(10.6 \%)$ \\
\hline \multicolumn{3}{|l|}{ MTHFR A1298C (rs1801131) } \\
\hline 1298AA & $133(54.7 \%)$ & $120(49.2 \%)$ \\
\hline 1298AC & $86(35.4 \%)$ & $105(43.0 \%)$ \\
\hline $1298 \mathrm{CC}$ & $24(10.0 \%)$ & $19(7.8 \%)$ \\
\hline \multicolumn{3}{|l|}{ Medications } \\
\hline Aspirin & $126(50.8 \%)$ & $137(54.8 \%)$ \\
\hline Clopidogrel & $42(16.8 \%)$ & $45(18.1 \%)$ \\
\hline Warfarin & $28(11.2 \%)$ & $21(8.4 \%)$ \\
\hline Beta-Blocker & $119(47.6 \%)$ & $141(56.6 \%)$ \\
\hline
\end{tabular}




\begin{tabular}{lcc}
\hline & $\begin{array}{c}\text { Nitrous Oxide/B- } \\
\text { Vitamins } \\
(\mathbf{n = 2 5 0})\end{array}$ & $\begin{array}{c}\text { Nitrous Oxide } \\
\text { /Placebo } \\
(\mathbf{n = 2 5 0})\end{array}$ \\
\hline ACE-Inhibitor & $94(37.6 \%)$ & $88(35.2 \%)$ \\
Statin & $130(52.0 \%)$ & $146(58.4 \%)$ \\
Diuretic & $79(31.6 \%)$ & $95(38.0 \%)$ \\
Surgical Procedure & & \\
$\quad$ Vascular & $76(30.4 \%)$ & $87(34.8 \%)$ \\
Orthopedic & $88(35.2 \%)$ & $81(32.4 \%)$ \\
ENT & $22(8.8 \%)$ & $20(8.0 \%)$ \\
Gyn. & $26(10.4 \%)$ & $21(8.4 \%)$ \\
Urology & $22(8.8 \%)$ & $22(8.8 \%)$ \\
$\quad$ Neurosurgery & $16(6.4 \%)$ & $19(7.6 \%)$ \\
\hline
\end{tabular}

ACE- angiotensin converting enzyme; ASA - American Society of Anesthesiologists classification; ENT - ear-nose-throat; IQR - interquartile range; $M T H F R$ - methylenetetrahydrofolate reductase gene; 


\section{Table 2}

Peak and change in plasma total homocysteine and high-sensitivity troponin T according to MTHFR genotype and intervention group

\begin{tabular}{llcc}
\hline & $\begin{array}{l}\text { MTHFR } \\
\text { Genotype }\end{array}$ & $\begin{array}{c}\text { Nitrous Oxide } / \mathbf{B}- \\
\text { Vitamins } \\
(\mathbf{n = 2 5 0})\end{array}$ & $\begin{array}{c}\text { Nitrous Oxide } \\
\text { /Placebo } \\
(\mathbf{n}=\mathbf{2 5 0})\end{array}$ \\
\hline Peak tHcy $(\mu \mathrm{mol} / \mathrm{L})$ & Homozygous & $16.5[13.3,21.2]$ & $17.4[12.8,21.1]$ \\
& Wildtype/Het. & $14.8[11.8,19.4]$ & $16.2[12.8,20.7]$ \\
Change tHcy $(\mu \mathrm{mol} / \mathrm{L})$ & Homozygous & $2.1[0,5.3]$ & $3.1[1.4,7.3]$ \\
& Wildtype/Het. & $2.1[-0.2,5.5]$ & $3.8[0.4,6.7]$ \\
& Homozygous & $19.1[13.3,34.2]$ & $14.5[10.0,24.0]$ \\
Peak hs-cTnT $(\mathrm{ng} / \mathrm{L})$ & Wildtype/Het. & $14.1[10.1,22.9]$ & $16.5[10.6,29.6]$ \\
& Homozygous & $3.6[1.3,13.4]$ & $2.9[1.3,6.2]$ \\
Change hs-cTnT $(\mathrm{ng} / \mathrm{L})$ & Wildtype/Het. & $2.4[0.3,5.8]$ & $2.5[0.5,7.1]$ \\
\hline & & &
\end{tabular}

Values are median and interquartile range. hs-cTnT- high sensitivity cardiac troponin T; MTHFR - methylenetetrahydrofolate reductase gene; tHcy - plasma total homocysteine; Homozygous= MTHFR 677TT or 1298CC patients; wildtype and het. (=heterozygous) $=$ MTHFR 677CC and TT; and $1298 \mathrm{AA}$ and AC. 
Table 3

Primary and secondary study outcomes grouped by MTHFR genotype and intervention arm.

\begin{tabular}{llccc} 
& & $\begin{array}{c}\text { Nitrous Oxide/ } \\
\text { B-Vitamins } \\
(\mathbf{n = 2 5 0})\end{array}$ & $\begin{array}{c}\text { Nitrous Oxide } \\
\text { /Placebo } \\
(\mathbf{n = 2 5 0})\end{array}$ & Sub-Total \\
\hline Cardiac Troponin Elevation & $\begin{array}{l}\text { Homozygous }(\mathrm{n}=98) \\
\text { Wildtype/Het. }(\mathrm{n}=389)\end{array}$ & $\begin{array}{c}27(13.8 \%) \\
5(11.1 \%)\end{array}$ & $29(14.1 \%)$ & $56(14.0 \%)$ \\
\hline & Sub-Total & $33(13.2 \%)$ & $34(13.6 \%)$ & $67(13.4 \%)$ \\
\hline Myocardial Infarction & Homozygous & $2(3.8 \%)$ & $1(2.3 \%)$ & $3(3.1 \%)$ \\
\hline & Wildtype/Het. & $5(2.5 \%)$ & $14(6.9 \%)$ & $19(4.7 \%)$ \\
\hline Length of Stay (days) & Sub-Total & $7(2.8 \%)$ & $15(6.0 \%)$ & $22(4.4 \%)$ \\
\hline
\end{tabular}

MTHFR - methylenetetrahydrofolate reductase gene;

Homozygous= MTHFR 677TT or 1298CC patients; wildtype and het. (=heterozygous)=MTHFR 677CC and TT; and 1298 AA and AC. 
Table 4

\section{Adverse Outcomes}

\begin{tabular}{|c|c|c|}
\hline & $\begin{array}{c}\text { Nitrous Oxide/ } \\
\text { B-Vitamins } \\
(\mathbf{n = 2 5 0})\end{array}$ & $\begin{array}{c}\text { Nitrous Oxide } \\
\text { /Placebo } \\
(\mathbf{n}=\mathbf{2 5 0})\end{array}$ \\
\hline \multicolumn{3}{|l|}{ Within 3 days after surgery } \\
\hline Nausea and vomiting - no. $(\%)$ & $3(1.2 \%)$ & $13(5.2 \%)$ \\
\hline Wound infection - no. (\%) & $3(1.2 \%)$ & $4(1.6 \%)$ \\
\hline Any pulmonary - no. $(\%){ }^{*}$ & $5(2.0 \%)$ & $4(1.6 \%)$ \\
\hline Any cardiovascular - no. $(\%)^{\dagger}$ & $16(6.4 \%)$ & $25(10.0 \%)$ \\
\hline Any renal - no. $(\%)$ & $5(2.0 \%)$ & $4(1.6 \%)$ \\
\hline Bleeding - no. $(\%)$ & $20(8.0 \%)$ & $14(5.6 \%)$ \\
\hline Ileus - no. (\%) & $4(1.6 \%)$ & $4(1.6 \%)$ \\
\hline \multicolumn{3}{|l|}{ Within 30 days after surgery } \\
\hline Readmission - no. (\%) & $9(3.6 \%)$ & $23(9.2 \%)$ \\
\hline Wound infection - no. (\%) & $15(6 \%)$ & $18(7.2 \%)$ \\
\hline Any pulmonary - no. $(\%) *$ & $3(1.2 \%)$ & $2(0.8 \%)$ \\
\hline Any cardiovascular - no. $(\%)^{\dagger}$ & $5(2.0 \%)$ & $11(4.4 \%)$ \\
\hline Any renal - no. $(\%)^{\dagger}$ & 0 & 0 \\
\hline Bleeding - no. $(\%)$ & $4(1.6 \%)$ & $2(0.8 \%)$ \\
\hline Ileus - no. (\%) & $1(0.4 \%)$ & 0 \\
\hline Deep venous thrombosis - no. (\%) & $2(0.8 \%)$ & $5(2.0 \%)$ \\
\hline Death - no. $(\%)$ & 0 & $3(1.2 \%)$ \\
\hline
\end{tabular}

* Pulmonary complications included respiratory distress, pulmonary oedema, pneumothorax, re-intubation, pneumonia, pleural effusion;

${ }^{\dagger}$ Cardiovascular complications included new onset atrial fibrillation, ventricular tachycardia, myocardial infarction, cardiac arrest;

† Renal complications included creatinine elevation, acute kidney failure, kidney injury during surgery 